\title{
INTERLIGAÇÕES GEOPOÉTICAS ENTRE SIMÕES LOPES NETO E JACK KEROUAC ${ }^{1}$
}

\author{
Geopoetic interconnections between Simões Lopes Neto and Jack Kerouac
}

Interconexiones geopoéticas entre Simões Lopes Neto y Jack Kerouac

Flávia Alexandra Radeucker Duarte $^{2}$

Graduanda em Letras na Universidade do Vale do Taquari - Univates flavia.duarte@universo.univates.br

Rosiene Almeida Souza Haetinger ${ }^{3}$ Professora Doutora de Letras na Universidade do Vale do Taquari - Univates rosiene@univates.br

\section{Resumo}

O presente artigo apresenta as interligações entre dois contos regionalistas a partir da linguagem desenvolvida em ambos, conhecida como geopoética, responsável por expressar através de descrições do ambiente seu sentimento de admiração e pertencimento ao lugar onde vivem. Os referidos contos são "Trezentas onças", de Simões Lopes Neto e "Sozinho no topo da montanha", de Jack Kerouac, que apesar de haverem sido publicados em contextos e épocas distantes, possuem similaridades muito significativas no que tange à poética da terra. A partir de referenciais teóricos como Milton Santos e Regina Zilberman, é esclarecido os conceitos de ambiente e espaço e a relação com o ser humano, observando como a literatura gaúcha e a Beatnik incorporam a imagética ao longo da sua história As interligações aqui analisadas mostram que a geopoética aproxima as obras por trazerem a natureza e o homem como figuras centrais que dialogam seus papéis e difundem sua expressão pela literatura.

Palavras-chave: Geopoética. Simões Lopes Neto. Jack Kerouac. Literatura gaúcha. Literatura beatnik.

\begin{abstract}
This paper presents the interconnections between two regionalist short stories based on the language used in both, which is known as geopoetics and is responsible for expressing the feeling of admiration and belonging to the place that one lives through environment description. The short stories are "Trezentas onças", by Simões Lopes Neto, and "Sozinho no topo da montanha", by Jack Kerouac, which have very significant similarities regarding earth poetics besides have been published in contexts and times far from each other. Based on theoretical references as Milton Santos and Regina Zilberman, the concepts of environment,
\end{abstract}

\footnotetext{
${ }^{1}$ Artigo acadêmico produzido na disciplina de Literatura Sul-rio-grandense.

${ }^{2}$ Univates, acadêmica do curso de Letras Português/Inglês, flavia.duarte@univates.br.

${ }^{3}$ Orientadora. Mestre em Literatura Comparada pela UFRGS, Univates, rosiene@univates.br.
} 
space and their relation to the human being are clarified showing how gaucho and Beatnik literature embody the images throughout their history. The interconnections here analyzed show that geopoetics bring closer the works by portraying the nature and the man as central figures that dialogue in their roles and disseminate their expression through literature.

Key words: Geopoetics. Simões Lopes Neto. Jack Kerouac. Gaucho literature. Beatinik literature.

\section{Resumen}

Este artículo presenta las interconexiones entre dos cuentos regionalistas a partir del lenguaje desarrollada en ambos, conocida como geopoética, que es responsable por expresar a través de descripciones del ambiente su sentimiento de admiración y pertenencia al sitio donde viven. Los cuentos referidos son "Trezentas onças", de Simões Lopes Neto, y "Sozinho no topo da montanha", de Jack Kerouac que, a pesar de haber sido publicados en contextos y tiempos distantes uno del otro, poseen semejanzas muy significantes en lo que toca a la poética de la tierra. Desde referenciales teóricos como Milton Santos y Regina Zilberman se esclarecen los conceptos de ambiente y espacio y la relación con el ser humano, buscando entender como la literatura gaucha y la Beatnik incorporan las imágenes a lo largo de su historia. Las interconexiones aquí analizadas muestran que la geopoética acerca las obras por traer la naturaleza y el hombre como figuras centrales que dialogan sus papeles y difunden su expresión por la literatura.

Palabras clave: Geopoética. Simões Lopes Neto. Jack Kerouac. Literatura gaucha. Literatura Beatinik.

\section{INTRODUÇÃO}

No universo literário, os elementos que circundam as obras têm relação com outras áreas: artes visuais, história, fotografia, música, entre outros. Uma relação, que alguns autores exploram, é com a natureza. Por esse viés, os movimentos literários regionais ao longo da história também se moldam nesse aspecto. A relação homem-terra surge como forma de valorização da natureza, não sendo característica de apenas um único grupo ou movimento. A geopoética ao longo da história acaba por vezes transmitindo um mesmo sentimento, o que traduz o impacto que a paisagem natural gera naqueles que a sentem e a vivenciam.

Neste trabalho pretende-se analisar as interligações geopoéticas presentes nos contos "Trezentas onças", de Simões Lopes Neto, e "Sozinho no topo da montanha", de Jack Kerouac. Em ambas as obras, a geopoética desenvolvida pelos autores transmite certa veneração aos elementos da natureza que circunda os personagens, apesar das diferenças temporais e contextos de publicação: o primeiro lançado em 1912, no Rio Grande do Sul, e o segundo em 1960, nos Estados Unidos. 
De início, é apresentado mais detalhes sobre as obras referidas, que integram a seleção de contos dos livros "Contos gauchescos \& lendas do sul” (2007) e "Cenas de Nova York e outras viagens" (2012). Em seguida, será apresentado com mais detalhes o desenvolvimento e aspectos da poética da terra na literatura, abrangendo depois mais diretamente as características de Simões Lopes Neto e Jack Kerouac, para serem identificadas e aproximadas as semelhanças entre as suas obras, trazendo também referenciais teóricos sobre a temática, como Milton Santos e Regina Zilberman. Como conclusão, pretende-se esclarecer a analogia entre os autores, que com obras tão singulares se aproximam no que se refere à imagética de sua terra e pertencimento.

\section{DA VIDA AOS CONTOS DE SIMÕES LOPES E KEROUAC}

Simões Lopes Neto (1865-1916), escritor natural de Pelotas, publica em 1912 a primeira edição da obra intitulada Contos gauchescos, considerado atualmente um marco na literatura regionalista. O repertório de contos é narrado, em sua maioria, pelo personagem Blau Nunes, figura cujos traços da imagem e comportamento do gaúcho são de certa forma enraizados, trazendo ênfase ao homem do pampa, que nutre laços fortes com a natureza que o cerca, aspecto de grande relevância nesta análise.

No conto que abre o livro, intitulado "Trezentas onças", Simões Lopes inicia a história com Blau Nunes chegando até o seu trabalho mais recente, "em Coronilha, por fevereiro". Sempre junto consigo "um cachorrinho brasino, um cusco mui esperto e boa vigia" (p. 18), elemento importante para a figura do gaúcho, que desempenha um papel decisivo na história, como será abordado posteriormente. O ápice da história vem logo em seguida, quando Blau Nunes esquece a guaiaca com trezentas onças de ouro que estava encarregado de entregar para o seu patrão.

Os elementos simbólicos oriundos da natureza que giram em torno da história se sobressaem a todo instante, provocando aproximação do leitor com o ambiente no qual o enredo se desenvolve, e principalmente, como estes conversam com o personagem. Simões Lopes busca descrever as formas que representam relações entre a personagem e o local onde está naquele instante, destacando tanto as vantagens quanto desvantagens.

Avançando alguns anos e muitos quilômetros, Jack Kerouac (1922-1969), nascido na cidade de Lowell, Massachusetts, nos Estados Unidos, após muitas desavenças resultantes de sua vida agitada, publica em 1960 seus relatos de viagem intitulado Cenas de Nova York, três anos depois da sua obra prima, On the road (1957, Estados Unidos). 
Kerouac foi um dos escritores protagonistas do movimento social e literário Beatnik, que provocou conflito de gerações em relação às atitudes de seus integrantes em relação à vida e à literatura (GIFFORD e LEE, 2013). A liberdade de experimentação formal na literatura Beat é um reflexo da busca pela liberdade de pensamento e de comportamento (GIFFORD e LEE, 2013), responsável por popularizar um estilo literário que transmitia as vivências dos autores com uma linguagem única, direta, popular e fora dos padrões norte-americanos da época.

A essência de sua obra está naquilo que envolvia suas experiências de vida, a partir do dia em que percebe ser a estrada e "o mundo lá fora" a resposta de muitas de suas perguntas. Desejando viver como os poetas americanos, mudou de endereço e libertou sua personalidade quando passa a frequentar bares e parques com nomes da literatura, como Allen Ginsberg (1926-1997), com quem manteve amizade até o final da vida. Com a influência de seus colegas de quarto na faculdade, Kerouac "decide viajar para o oeste rumo à fronteira que ele imaginava restar ali [...], essa foi a simples equação da amizade entre Jack e $\mathrm{Neal}^{4}$ [Cassady] que levou Kerouac à produção de seu melhor trabalho" (GIFFORD e LEE, 2013).

Os reflexos de suas aventuras existenciais estão profundamente relacionados aos ambientes por onde passou, seja as grandes metrópoles, porões de navios, fábricas e, principalmente, florestas selvagens. Em seu conto Sozinho no topo da montanha (2012), Kerouac traz o relato de experiência dos três meses que passou sendo vigia de incêndios em uma montanha, longe do caos urbano, na Floresta Nacional de Mount Baker, em Seattle, como pretexto para passar um longo período sozinho em contato apenas com a natureza, buscando fugir da turbulência das metrópoles e buscar algo dentro de si, através daquilo que apenas o ambiente natural e isolado lhe transmitia.

Assim como Simões Lopes, Kerouac utiliza os elementos da paisagem natural por meio da narração em seu conto para simbolizar aspectos da essência da história que está contando, como assimilam as conexões de seu espírito com os elementos do ambiente, de forma poética e livre, até certo ponto despretensiosa, mostrando que sem a natureza o homem não poderia compreender sua razão de ser e estar ali.

\footnotetext{
${ }^{4}$ Nascido em 1928, Neal Cassady foi amigo próximo de Jack Kerouac, que o acompanhou na sua grande viagem pelos Estados Unidos, inspirando a criação de vários personagens em suas obras, como Dean Moriarty no livro On the road (1957), sendo também referido nos poemas Howl de Allen Ginsberg e Hell's Angels de Hunter S. Thompson. Publicou no total seis obras, entre elas Joan Anderson Letter (1950) e Pull My Daisy (1951). Faleceu em 1968, em decorrência de uma mistura fatal de drogas e álcool, logo após sair de uma festa de casamento.
} 


\section{A LINGUAGEM GEOPOÉTICA}

Milton Santos, em A Natureza do Espaço: Técnica e Tempo, Razão e Emoção (2008), analisa o espaço como um conjunto indissociável de objetos e ações, a partir da concepção e noções sobre técnicas e tempo, razão e emoção, propondo um sistema para entender o espaço geográfico. Em determinada parte da obra, Santos explica a diferença entre paisagem e espaço, pontos de vista a serem considerado neste trabalho. Comenta que “a paisagem é o conjunto de formas que exprimem as heranças que representam as sucessivas relações localizadas entre o homem e natureza", e o espaço "são essas formas mais a vida que as anima" (2008, p. 103).

A paisagem e o espaço influenciam diretamente nas percepções do ser humano sobre aquilo que está ao seu redor por manterem ligação direta, uma vez que o espaço é a sociedade, uma vez que a paisagem também o é (SANTOS, 2008). Dessa forma, as vivências relatadas nos contos "Trezentas onças" e "Sozinho do topo da montanha" abarcam suas percepções quanto à paisagem e o espaço ao longo dos textos, caracterizandose como geopoética.

Em seus estudos sobre imagética na Literatura Sul-rio-grandense, Menegusso (2011) diz que “a introdução da geografia no meio literário acarreta transformações, principalmente, no domínio da estética e da identidade cultural". Simões Lopes Neto e Jack Kerouac, apesar de pertencerem a movimentos literários distintos, incorporam tais elementos de modo similar em seus contos, onde a natureza possui caráter essencial. $\mathrm{O}$ entrelaçamento entre a literatura e a geografia de ambos os autores possui um histórico marcado pelo relato de experiências regionais, o que significa que registraram o espaço que habitaram e pertenceram ao longo de suas obras.

A “poética da terra", segundo Menegusso, são representações paisagísticas repletas de significados e sentidos que podem ser expressados através da literatura de um povo, em determinada época e região. Muitos estudos sobre a geopoética na literatura sul-riograndense foram e vêm sendo produzidos, uma vez que a temática é de grande importância para a identidade e história gaúcha. A representação das paisagens está presente em grande parte das obras de renome da literatura nacional e gaúcha, mas em contraponto, os Beatniks não foram levados tão a sério quando iniciaram seus trabalhos e intervenções literárias, e os estudos sobre o movimento voltam-se geralmente para outros elementos das narrativas, como ascensão social, crimes e drogas. 
Regina Zilberman também voltou seus estudos para explanar mais a respeito da geopoética presente na literatura gaúcha, analisando a historicidade ${ }^{5}$ e obras específicas, como em seu livro A Literatura no Rio Grande do Sul (1982), realizando a análise de diversas obras pertencentes à literatura regional. Quanto à geopoética presente no conto de Simões Lopes, a autora define que o ideal mais forte é o amor à vida e à natureza (ZILBERMAN, 1982). Nele, a natureza tem sua linguagem própria, com sinais que o personagem interpreta a fim de situar-se no mundo, e é exatamente o que se percebe no conto de Kerouac também, o que torna as representações imagéticas muito semelhantes.

Zilberman comenta que "a paisagem é uma extensão da personalidade do herói ou do sentimento da história" ao analisar que o ambiente não é um objeto de descrição distante do narrador. Em outras palavras, ela possui caráter mítico, pois desempenha o aspecto de revelação vivenciada nos contos. Este fato, segundo a autora, explicaria a universalidade atribuída ao lugar da ação.

\section{A INTEGRAÇÃO HOMEM-TERRA EM "TREZENTAS ONÇAS"}

O conto de Simões Lopes é narrado em primeira pessoa pelo personagem Blau Nunes, como já citado anteriormente. Nesta história, Blau relembra uma de suas aventuras vividas pela região do pampa gaúcho, na qual era responsável por entregar uma guaiaca com o dinheiro de um patrão. Inicia o relato descrevendo a paisagem com que se deparou em dada parte do percurso: na restinga, à sombra daquela mesma reboleira de mato, e sentindo-se muito bem para descansar ali, adormece. O que lhe acorda é "o ruído manso da água tão limpa e tão fresca" (2007, p. 5), convite para se banhar ali, bem como para um descanso. Em seguida, arruma seus pertences e retoma o caminho.

Quando Blau Nunes já está longe do local onde descansou, suspeita de alguma coisa errada, já que o seu companheiro, um "cachorrinho brasino, um cusco mui esperto e boa vigia" (2007, p. 5), não parava de alertá-lo sobre algo urgente. O cachorro tentando chamar sua atenção perdura até o momento em que chegam na estância do patrão, e finalmente compreende o seu companheiro: a guaiaca com as trezentas onças foi esquecida, e sente-se imediatamente arrependido de não ter observado seu erro antes.

\footnotetext{
5 No Estado do Rio Grande do Sul, a partir da metade do século XIX, a fundação da Sociedade Partenon Literário, espécie de comunidade cultural local como veículo de comunicação, é a responsável pela introdução de temas regionais, principalmente relativos à paisagem, na literatura local. E como a "poética da terra" trespassa as partes do mundo, o mesmo ocorre em outras regiões, em outras épocas, mostrando ser parte na vida dos autores que aqui serão tratados, Simões Lopes Neto e Jack Kerouac.
} 
Blau Nunes mostra o quanto isso lhe afeta, seus sentidos ficam atrapalhados, afinal é um homem simples, e o receio do que podem lhe culpar aperta seu coração. Em outra passagem da história, comenta com um amigo que preferia ser morto do que chamado de ladrão. Nesse momento, vê que o seu cachorro novamente lhe mostra o que deve ser feito: aponta para o cavalo, indicando para retornar o mais breve ao lugar onde esteve descansando, lugar onde esqueceu as trezentas onças.

Quando parte em direção à sanga, encontra uma comitiva de tropeiros, com quem apenas comprimenta "tocando na aba do sombreiro". O tempo estava passando depressa, como sugere quando observa que "o cachorrinho ia ganiçando, ao lado, na sombra do cavalo, já mui comprida”, indicando que estava já anoitecendo.

Nesta passagem do conto, o autor passa a destacar diretamente sobre a paisagem que está ao seu redor, descrevendo o caminho que Blau Nunes está percorrendo em busca da guaiaca:

A estrada estendia-se ali deserta; à esquerda os campos desdobravam-se a perder de vista, serenos, verdes, clareados pela luz macia do sol morrente, manchados de pontas de gado que iam se arrolhando nos paradouros da noite; à direita, o sol, muito baixo, vermelho dourado, entrando em massa de nuvens de beiradas luminosas. (LOPES NETO, 2007, p. 19)

Os aspectos do pampa conversam com o personagem, de modo que a forma como os detalhes ao mesmo tempo que está acostumado a presenciar e viver nele ainda despertam um sentimento nostálgico, se sente tocado pela beleza do campo. E ainda acrescenta:

Nos atoleiros, secos, nem um quero-quero: uma que outra perdiz, sorrateira, piava
de manso por entre os pastos maduros; e longe, entre o resto da luz que fugia de
um lado e a noite que vinha, peneirada, do outro, alvejava a brancura de um joão-
grande, voando, sereno, quase sem mover as asas, como uma despedida triste, em
que a gente também não sacode os braços. (LOPES NETO, 2007, p. 19)

Acrescenta ao final deste trecho que "foi caindo uma aragem fresca, e um grande silêncio, em tudo" (2007, p. 6), mostrando que a imensidão ao seu redor o leva à conclusão de sua condição, o ambiente o induzia a refletir sua situação. Acrescenta: "e o sol entrou; ficou nas alturas um clarão afogueado, como de incêndio num pajonal", o reflexo do final do dia mexia com seu espírito, “depois o lusco-fusco; depois; cerrou a noite escuro; depois, no céu, só as estrelas... só as estrelas...” (p. 19), o tempo passando o intimidava, e vê-lo diante de seus olhos através de elementos simbólicos alude à um certo grau de imponência. 
Os elementos da paisagem natural influenciam os pensamentos do personagem, e quando Blau Nunes olha para o céu, agora de noite, vê "bem por cima de sua cabeça as Três-Marias (...), lembrei-me dos meus filhinhos, que as estavam vendo, talvez". O símbolo que os conecta está presente tanto para o homem quanto para os seus filhos, e vai além, pois também o faz lembrar de seus pais, que viram o mesmo céu em outra época. A nostalgia que sente é firmada quando diz para o leitor “Amigo! (...) Deus o conserve,... sem saber nunca como é pesada a tristeza dos campos quando o coração pena" (2007, p. 20).

Nesse ponto da história, o personagem já se sente tão desolado a ponto de encher os olhos de lágrimas, como parte de seu desespero pela fortuna perdida. Essas lágrimas caem na estrada em que passava, marcando o chão como ponto final de sua busca. Tudo ao seu redor parece ter desistido também: o cavalo "respirou fundo e sentou, o cachorro "respirando como assoleado" (2007, p. 7), e ao redor apenas o silêncio, entre as sombras do arvoredo, que agora lhe causavam medo.

Já alcançado o lugar onde havia feito seu descanso horas atrás, foi localizando-se na escura noite pelo tatear, tentando encontrar a guaiaca. Sem êxito, lhe ocorre uma única solução, que tenta distanciar do pensamento quando olha para "o cachorrinho tão fiel, que lembra a amizade da minha gente; o meu cavalo lembrou-me a liberdade, o trabalho". São esses elementos que despertam nele, naquele momento, a lembrança do motivo que não deve desistir, assim como afirma ainda neste trecho: "e aquele grilo cantador trouxe a esperança" (2007, p. 21).

Blau Nunes, como figura representativa do gaúcho do pampa, possui um dos aspectos mais marcantes de personalidade tradicional na literatura, a honra. Ao cogitar a ideia de que seu patrão e todos com quem trabalha iriam considerá-lo um ladrão, até mesmo um traidor, prefere estar morto do que receber essa sina. De súbito, desistindo efetivamente da sua intenção, reflete: "e já todo no meu sossego de homem, meti a pistola no cinto" (2007, p. 7).

Quando se dirige até o seu cavalo para retornar, o cachorro expressa felicidade em vê-lo novamente. E o mesmo faz quando chegam à porteira do rancho, onde os animais reconhecem a chegada. Ao entrar na casa, vê seus companheiros, com quem havia se encontrado momentos antes, e percebe que eles haviam encontrado sua guaiaca e tomaram cuidado em devolvê-la para Blau Nunes, que sente o peso sair das suas costas quando tudo se resolve. 


\section{A INTEGRAÇÃO HOMEM-TERRA EM "SOZINHO NO TOPO DA MONTANHA"}

O texto de Jack Kerouac é narrado em primeira pessoa, e conta uma das aventuras vividas pelo próprio autor em sua juventude. Inicia relatando sobre a sua necessidade de se afastar do modo que está vivendo, que precisa retirar-se da agitação das metrópoles, livrando-se dela. Por ser um texto mais extenso que o primeiro conto analisado, algumas passagens serão resumidas e outras não serão abordadas, concentrando apenas as passagens com foco maior na geopoética.

No início do texto, Kerouac descreve do ponto de vista geográfico o caminho percorrido até as montanhas High Cascades, em Seattle, para encontrar um colega que o levaria até o seu posto de trabalho como guarda florestal. A linguagem utilizada logo de início mostra a sensibilidade com que percebe a paisagem ao longo da viagem, descrevendo que “(...) subitamente surgem as Cascade Mountains se erguendo no horizonte (...). Os grandes picos cobertos de alvura intocada, um universo de enormes rochedos retorcidos e amontoados e às vezes quase espiralados em formações fantásticas e inacreditáveis." (2012, p. 26).

Para Kerouac chegar até a região, percorre de carro os vales Stilaquamish e Skagit. Assim como Blau Nunes, observa os dois lados da estrada quando está retornando à sanga onde esquecera a guaiaca: "à esquerda, o Skagit corre para a baía e mergulha no oceano. (...) você vira para a direita e segue direto para o coração das montanhas por uma estrada rústica dentro do vale cruzando cidadezinhas sonolentas". A escolha de palavras mostra a sutileza que o autor dedica para deixar sua descrição precisa, o que permite ao leitor melhor visualização e interpretação.

Ao contrário de Blau Nunes, a solidão como consequência era seu objetivo, uma necessidade. Kerouac diz que "estava em busca de uma experiência que os homens raramente obtêm nesse mundo moderno: solidão completa e tranquila em meio a um ambiente selvagem, dia e noite, sessenta e três dias e noites, para ser exato" (2012, p. 30). Mesmo com as advertências do seu guia quanto ao isolamento por um longo período, resolve manter sua decisão, e ainda ironiza, se intitulando de viajante solitário.

Quando começam a se dirigir para o Desolation Peak, o qual Kerouac é encarregado de vigiar, descreve com detalhes os desafios impostos pela natureza que ele e seu guia encontram:

Depois de duas horas enfrentando ondas tempestuosas do longo lago fustigado pela chuva, com soturnas florestas nebulosas se erguendo íngremes em ambas as margens e as mulas e cavalos com o focinho metido nos sacos de ração e suportando 
pacientemente a chuvarada, chegamos ao sopé da trilha do Desolation, e o homem do rebocador (que nos proporcionou um bom café na cabine do piloto) manobrou de maneira a encostar a balsa de lado em uma ladeira lamacenta e íngreme, repleta de arbustos e árvores caídas (KEROUAC, 2012, p. 31).

Quando começam a subida até o topo da montanha, Kerouac traz mais descrições dos desafios, relatando os detalhes que o impressiona, como os "prados alpinos e salpicados e tremoceiros azuis na névoa espessa” (2012, p. 20), e também quanto ao clima, quando "subitamente uma grande ventania arrojou rajadas de granizo contra nós"(2012, p. 20), indício de que estavam se aproximando do cume. Ao chegarem no local, se surpreende com a atmosfera do lugar: "lá está ela [a cabana], acima, na penumbra da montanha, um pequeno barraco de telhado pontiagudo, isolado no topo do mundo" (2012, p. 32).

Quando “a escuridão baixou, incompreensível” (2012, p. 21), já antecipa seu sentimento dos próximos três meses. O isolamento completo do resto do mundo dá indício no segundo dia, numa manhã cinzenta, em que deu "vinte cuidadosos passos em cada direção do pátio da cabana, cujas extremidades pareciam ser quedas livres em precipícios silenciosos" (2012, p. 21).

A paisagem da montanha Mount Baker o estremece, toda a imensidão diante de seus olhos foi "um pouco demais para um garoto urbano" (2012, p. 22), como ele mesmo diz. As descrições passam a aprofundar mais a geopoética neste trecho do conto, quando relata o que vive no dia seis de julho:

Fiquei surpreso e eufórico ao ver o céu azul límpido e ensolarado e lá embaixo, como um mar de neve radiante e pura, as nuvens dispostas como uma cobertura de marshmellow sobre o mundo todo e o lago inteiro, enquanto eu permanecia sob o sol cálido, em meio, em meio a centenas de quilômetros de picos alvos de neve.

Ao meio dia as nuvens se dissiparam e o lago surgiu lá embaixo, inacreditavelmente belo, uma piscina de perfeito azul com quarenta quilômetros de comprimento ou mais, e os córregos como córregos de brinquedos, e a mata verde e viçosa por toda a parte, e até os alegres rastros líquidos dos barcos de pesca dos veranistas que riscavam o lago e as lagunas. Uma tarde ensolarada perfeita (KEROUAC, 2012, p. 34).

Por se tratar de um ambiente relativamente hostil, na natureza fechada, havia junto de todo o encanto da montanha as dificuldades de morar ali. Ser guarda de incêndio florestal o colocou em situações difíceis, como quando enfrentou uma forte tempestade, em que "sentia a terra tremer" (2012, p. 22) com os relâmpagos, e em certa manhã quando vê 
os rastros de um urso, que "devia se aproximar sorrateiro" (2012, p. 25) a qualquer momento.

Kerouac passa a descrever também a sua rotina, que consistia em informar precisamente os focos de incêndios causados por raios. Descreve também o que costumava fazer ao longo do café da manhã, almoço e janta, além dos vários momentos de reflexão. Diz que "às vezes gritava perguntas às rochas e às árvores dos desfiladeiros, ou cantava como um tirolês”, e se perguntava “"o que significa o vazio?’ e a resposta era o silêncio perfeito, e então eu entendia" (2012, p. 36).

Ao longo do conto, desenvolve sua sensibilidade de modo muito simbólico em relação aos elementos da natureza, como quando observa ao seu redor "as montanhas como sinfonias de neve rosada", podendo-se observar que agora ele faz parte da paisagem, "batizando" uma montanha com seu nome e outras com nomes figurativos, como se fossem seus amigos próximos. Também continua observando "o silêncio dos insetos em homenagem à lua" (2012, p. 24), os "sessenta e três poentes loucos e fogosos despejando-se como espuma do mar de nuvens através de penhascos inimagináveis, as manhãs frias com nuvens encapeladas" (2012, p. 24).

O urso é um dos símbolos mais curiosos que está presente no relato, o qual Kerouac chama de "Urso Primordial", pois "dominava todo o Noroeste e todas as neves, era o senhor de todas as montanhas" (2012, p. 39). Sabia que ele mesmo era o verdadeiro intruso ali, contando sobre os ursos terem um vastíssimo histórico de permanência naquelas montanhas. Tinha medo principalmente à noite, quando "podia ouvir através da montanha sob a luz das estrelas" (2012, p. 25) a boca do urso mastigar, e faria de tudo para evitar que um dia sua cabeça virasse alimento.

A solitude do autor permanece sendo transmitida quando comparada ou refletida através de algum elemento que está ao seu redor ainda em outros trechos, como quando diz: “que estranhos e doces pensamentos brotam nas solidões montanhosas!” (2012, p. 40). Na sequência deste trecho, as suas percepções sobre o comportamento humano em relação a aspectos como humildade e individualidade são transcritas de forma livre, quase sem pausas (ressaltando uma das características principais da escrita de Kerouac e dos Beatniks). É quando passa a ver com outros olhos o que atingir esta montanha quer dizer. Reflete religiosamente sua concepção de Universo e Deus para justificar a imensidão da existência e parece estar em paz ao fazê-lo. 
Ao final do conto, assim como Simões Lopes, compreende a experiência com um olhar mais leve e evoluído. No final da aventura, observa o aspecto geral da montanha, a sua cabana agora escondida pela neve densa, e pode apenas sentir-se grato "pelo abrigo e pela lição que ensinaram" (2007, p. 42).

\section{CONSIDERAÇÕES FINAIS}

A geopoética é uma temática que possui longo histórico na literatura nacional e internacional, tanto abrangida nas obras dos autores referidos neste trabalho quanto de demais autores que pertenceram aos mesmos movimentos literários. Quando se trata das obras Contos gauchescos \& lendas do sul (2007) e Cenas de Nova York e outras viagens (2012), que pertencem a movimentos literários tão distintos, ainda podemos observar semelhanças quanto à relação que os autores possuem com o ambiente em que passam suas vidas, e que acabam influenciando suas obras de modo simbólico e profundo.

Assim como referido no início deste trabalho, a análise dos contos de Simões Lopes e Kerouac possui o intuito de interligá-los através do sentido que a paisagem e espaço transmitem, que Milton Santos (2008) define como transtemporal. Posteriormente, analisou-se que tal interligação caracteriza-se como geopoética, analisada com mais especificação por outros autores que pesquisam a temática, como Regina Zilberman, adentrando também aspectos sociais em torno da poética da terra.

As interligações geopoéticas presentes entre "Trezentas onças" e "Sozinho no topo da montanha" partem da linguagem utilizada pelos autores para demonstrarem como se sentem imergidos na natureza. A transmissão dos sentimentos e novas percepções quando se inserem no ambiente, como cita Menegusso (2011), é permitida pela imagética presente em ambos os textos. $\mathrm{O}$ autor diz também que a geografia causa tais transformações no domínio desta estética, pois se tratam de experiências regionais, e os autores não apenas ouviam falar ou leram sobre as montanhas ou os pampas, mas de fato viveram nestes ambientes.

A vivência dos personagens dos contos se passa em locais semelhantes: na natureza rústica, o que exige outro olhar para a sobrevivência. Tanto Blau Nunes quanto Kerouac permanecem todo o tempo nestes ambientes, realizando um trabalho para eles temporário, mas que a natureza exige: levantar gado e vigiar focos de incêndio florestal. São homens simples e pobres, que não se prendem em meios urbanos e realizam seus ofícios para terem 
como se manter temporariamente, e que segundo Menegusso (2011), representam os grupos sociais a qual pertenciam.

A jornada de ambos em razão do trabalho a céu aberto e a solidão são algumas das consequências, não exatamente positivas, nem negativas. Kerouac buscou o emprego para ficar isolado propositalmente, de forma que o seu guia da montanha o adverte logo no início da trajetória: "vamos te levar para onde não podemos te resgatar - é melhor que você se prepare" (p. 29). E Simões Lopes mantém o personagem Blau Nunes solitário para fixar os traços da personalidade guasca tradicionalista.

Sobre a solidão, Kerouac traz uma passagem representativa, ao afirmar que "nenhum homem devia passar pela vida sem experimentar pelo menos uma vez a saudável e aborrecida solidão em um lugar selvagem" (2012, p. 37). Quando passa os três meses no topo da montanha, alcança a sabedoria que não poderia atingir vivendo na metrópole, e Blau Nunes precisou passar por momentos de reflexão sozinho para compreender a importância de sua família, de seus amigos, e de sua vida, acima de tudo.

Como característica típica do gaúcho da campanha e companhia fiel, Blau Nunes possui o seu cachorro, que mostra entender a situação e avisa o dono de seu engano, e também possui o seu cavalo, necessário para cuidar do gado e como meio de locomoção no pampa, visto como uma extensão do peão. Kerouac, habitante da montanha por três meses, sabia que naquele ambiente há ursos selvagens, já que conhece o histórico dos verdadeiros "donos" da região, chamando um deles que parecia se aproximar de "Urso primordial" (2012, p. 39).

A minuciosidade dos detalhes da natureza, como visto ao longo da análise dos contos, nos permite interpretá-los de modo claro, já que a imagética desenvolvida pela geopoética é muito profunda. Como dito anteriormente, a solidão os faz pensar de uma forma diferente, perceber o mundo ao seu redor com um olhar único, interpretar os sinais que a natureza demonstra. Para Blau Nunes, observar o cansaço do seu cavalo, do cachorro e o barulho dos insetos o faz compreender a beleza de viver, que não valia a pena terminar tudo ali por impulso. E para Kerouac, que tinha uma missão espiritual, compreende a razão de estar ali quando "gritava perguntas às rochas e às árvores dos desfiladeiros o que significa o vazio?' e a resposta era o silêncio perfeito, e então entendia" (2012, p. 36). Ou seja, alcança a compreensão completa através da natureza em que estava. $\mathrm{O}$ aspecto de revelação presente nas obras, como afirma Zilberman (1982), se deve ao fato de estarem 
inseridos no ambiente que proporciona a natureza. Uma vez que passam a viver nestes espaços, adquirem a compreensão de diversos aspectos psicológicos que os rodeiam.

A riqueza dos detalhes trazidos também nos coloca no lugar dos personagens. $\mathrm{O}$ pampa gaúcho e as montanhas de Seattle são únicos, e ambas as paisagens impressionam os personagens. Também é importante mencionar que, conforme a época e o trabalho desenvolvido em cada uma das histórias, os personagens precisam adaptar suas rotinas conforme o ambiente. Essa adaptação se deve pelo ofício que realizam, bem como para permanecerem longos períodos de tempo ali.

Uma das passagens que possui grande semelhança imagética nos contos referidos é quando olham para o céu e refletem. Blau Nunes, quando está prestes a desistir da busca, olha "a noite escura, e depois, no céu, só as estrelas... só as estrelas..." (2007, p. 19). E Kerouac, "através da montanha sob a luz das estrelas" (2021, p. 39), vê a imensidão que existe diante de seus olhos. Pode-se observar também que há semelhança na forma como vêem os últimos raios de sol do dia: o reflexo final do dia mexia com o espírito de Blau Nunes "depois do lusco-fusco" (2007, p. 6), e Kerouac voltava sua atenção todos os dias "poente brilhante e soturno muito além das palavras" (2012, p. 38).

Quanto aos Beatniks, há poucos estudos aprofundados sobre a sua literatura, que, como dito anteriormente, tendem a focar apenas em outros aspectos do movimento, como o comportamento e relações com drogas. Há obras cinematográficas que exploram mais a vida pessoal e criativa de poucos autores que integraram os Beats, como "Versos de um crime" (2013), dirigido por John Krokidas, e conta com Jack Kerouac como figura secundária. Um dos objetivos deste trabalho é realizar uma análise literária mais aprofundada de uma das obras de Jack Kerouac, um dos primeiros Beatniks, com intuito de trazer mais estudos sobre esse icônico e singular autor.

Já a literatura sul-rio-grandense possui um campo específico de estudos por ter um movimento literário reconhecido nacional e internacionalmente. Desde a fundação da Sociedade Partenon Literário, em junho de 1868, a produção literária e cultural, tem uma vasta área de estudos desenvolvidos, como, por exemplo, a obra A literatura no Rio Grande do Sul (1982), de Regina Zilberman, utilizada como uma das principais referências bibliográficas para esta pesquisa.

Zilberman afirma que "a natureza adquire dimensão mítica, revelando a presença de uma mentalidade primitiva, coerente com a circunstância de onde provém o herói das narrativas" (1982, p. 40). Dessa forma, a atmosfera que envolve "Trezentas onças" e 
"Sozinho no topo da montanha" possui caráter simbólico intrínseco com a geopoética, pois ambos os autores das obras viveram nos referidos espaços.

Posto que a geopoética está presente de forma muito similar nos contos de Simões Lopes Neto e Jack Kerouac, conclui-se que a leitura e análise detalhada embasada em autores que se voltam para esta área comprova que as interligações entre os referidos contos são nítidas, observando-se grandes semelhanças quanto à personalidade dos personagens e de suas experiências de imersão na natureza, bem como os impactos relatados, demonstradas ao longo das obras.

\section{REFERÊNCIAS}

GIFFORD, Barry. O livro de Jack: uma biografia oral de Jack Kerouac / Barry Gifford, Lawrence Lee; tradução Bruno Gambaroto. São Paulo: Globo, 2013. - il.

KEROUAC, Jack. Cenas de Nova York e outras viagens / Jack Kerouac; tradução de Eduardo Bueno. Porto Alegre: L\&PM, 2012.

KEROUAC, Jack. On the road: pé na estrada. Porto Alegre: L\&PM, 2007.

LOPES NETO, João Simões. Contos Gauchescos \& Lendas do Sul / Simões Lopes Neto - Porto Alegre; L\&PM, 2007.

MENEGUSSO, Gustavo. MÜLLER, Nelci. A geopoética na literatura gaúcha: uma leitura da paisagem nos romances Ana Terra e Ana Sem Terra. R. Língua \& Literatura. Frederico Westphalen. vol. 13, n. 20, p. 109-123. Ago. 2011.

SANTOS, Milton. A Natureza do Espaço: Técnica e Tempo, Razão e Emoção. 4 ed. 4 reimp. - São Paulo: Editora da Universidade de São Paulo, 2008. - (Coleção Milton Santos; 1)

ZILBERMAN, Regina. A literatura no Rio Grande do Sul. 2. ed. Porto Alegre: Mercado Aberto, 1982.

L\&PM EDITORES. Vida e obra: Neal Cassady. L\&PM Editores, 2021. Disponível em: https://www.lpm-

editores.com.br/site/default.asp?TroncoID $=805134 \&$ SecaoID=948848\& $\&$ SubsecaoID $=0 \&$ Template $=$ ../livros/layout_autor.asp\&AutorID=606063. Acesso em: 01 jul. 2021. 
Original recebido em: 01 de junho de 2020

Aceito para publicação em: 22 de julho de 2021

\section{Flávia Alexandra Radeucker Duarte}

Graduanda em Letras Português/Inglês e respectivas literaturas na Universidade do Vale do

Taquari - Univates.

\section{@ $(\Theta \otimes(0)$}

Esta obra está licenciada com uma Licença

Creative Commons Atribuição-NãoComercial-CompartilhaIgual 4.0 Internacional 